\title{
Lived experience of women who underwent early removal of long-acting Contraceptive Methods in Bedesa town, Wolaita Zone, Southern Ethiopia: A phenomenological study
}

Mohammed Suleiman Obsa ( $\sim$ msuleiman43@gmail.com )

Wolaita Sodo University https://orcid.org/0000-0002-6579-1136

Kassahun Tekle Takiso

Wolaita Sodo University

Tamiru Tilahun Ayele

Wolaiat Sodo University

Hailu Chare Koyra

Wolaita Sodo University

Kasahun Tafesse Hidota

Wolaita Sodo University

Getahun Molla Shanka

Wolaita Sodo University

Lolemo Kelbiso Hanfore

Wolaita Sodo University

Mihiretu Alemeyehu Arba

Wolaita Sodo University

Antehun Alemeyehu Anjulo

Wolaita Sodo University

Zewde Zema kanche

Wolaita Sodo University

Melkamu Worku kercho

Wolaita Sodo University

Research

Keywords: Family planning, long-acting family planning method, early removal, Bedesa

Posted Date: August 13th, 2020

DOI: https://doi.org/10.21203/rs.3.rs-29638/v2 
License: (c) (i) This work is licensed under a Creative Commons Attribution 4.0 International License. Read Full License 


\section{Abstract}

Background Long-acting contraceptive methods can play a pivotal role in reducing maternal mortality. In Etiopia, the total fertility rate per woman is 4.6 . However, this rapid population growth is not in line with the weak economic growth of the country. Therefore, this study was done to explore the lived experiences of women who underwent early removal of long-acting contraceptive methods in Bedesa town, Southern Ethiopia.

Methods A phenomenological study design was employed to include a total of 10 in-depth interviews of sampled women. Participants were recruited through criterion sampling method. Open code version 4.03 was used to code and facilitate analysis. Transcripts were read and re-read separately to identify emerging themes. Thematic analysis technique was used.

Results This study revealed that the side effect of the long-acting family planning methods were the main reason for early removal. Furthermore, heavy and irregular menses were mentioned as the most frequently occurred side effects. Delayed fertility after removal of long-acting contraceptive was one of frequently stated fear by the clients. It was also stated that counseling provided by health professionals was not adequate.

Conclusion The majority of study participants taught that the side effects of long-acting family planning methods outweigh the benefits. Besides, the counseling services provided by health care providers were not adequate. Therefore, proper counseling services should be given to mothers who are taking longacting family planning methods.

\section{Introduction}

Family planning (FP) is a low cost yet effective method of preventing maternal health problems [1, 2]. There are two types of contraceptives methods; namely short acting and long-acting and permanent methods. Long-acting methods can be used for both limiting and spacing childbirth, while permanent methods used only for limiting childbirths. Short-acting methods are suitable for women who want to space childbirths [3].

Long-acting contraceptive methods can play a key role in reducing maternal mortality. It can also significantly reduce the number of unintended births[4]. Moreover, avoiding barriers to the use of contraceptives and enhancing the demand for family planning could prevent 54 million unintended pregnancies. Besides, it could prevent more than 79,000 maternal and one million infant death per year [5].

In Ethiopia, it is common to have a large family size with a shorter birth-interval. The total fertility rate in Ethiopia is as high as 4.6 children per woman. However, this rapid population growth is not in line with the weak economic growth of the country. Such imbalance between population size and economic 
growth will certainly have a negative impact on the wellbeing of the nation. Family planning is considered as the key strategy used to improve the imbalance mentioned above and tackle existing problems [6].

According to the EDHS 2016 report, the discontinuation rate of Implant and IUD was 35\% and $11 \%$ respectively. Another mixed method study conducted by FMOH showed that $17 \%$ of the women removed their Implanon before the recommended removal date [7]. A similar study conducted in the Tigray region showed that the Implanon discontinuation rate in 1 year was $16 \%[8,9]$. The most common reason for discontinuation are the desire to become pregnant, side effects, wanting a more effective method, infrequent sex or husband away, and inconvenience of use [10].

Wolaita Zone is characterized by a crude population density of 385 people/square kilometer [6]. Since providing the most effective contraceptive methods is a vital strategy for the improvement of balancing population growth with the economic growth of the locality. Thus,this study was aimed to explore the lived experience of mothers who underwent early removal of long acting contraceptive methods in the study area.

\section{Methods And Materials}

A phenomenological study design was used to explore the lived experience of sampled women in Bedesa town, southern Ethiopia. Those women aged 15-49 years who removed long-acting in the past 12 months were included. A criterion sampling approach was employed to recruit 10 participants. The interview continued until information saturation was reached. Data were collected through in-depth interviews (IDIs) using an interview guide. The interview guide consists of on basic socio-demography, desire for family size, knowledge and experiences of family planning, advantages, perceived side effects of long-acting family planning, perceptions about FP, partner involvement and peer pressure concerning the use of family planning, professionals support and plan on family planning. This recruitment was facilitated through the head of health center. Every study participant was encouraged to openly discuss their opinions. All interviews were conducted in a separate quiet room to avoid interruption from outside. Each IDI lasted for approximately 30 to $38 \mathrm{~min}$. Each team checked the contents of the respective interviews. Interviews were conducted in the Amharic language. The free flow of information was encouraged through probing. To ensure the quality of the interviews, interviewers repeated the summary of interview to study participant. The team members checked the text of each interview twice. All interviews were tape-recorded with the consent of interviewees. A unique identification number was assigned to all the recorded files. Audio data were transcribed verbatim and translated to English. The data were first saved in plain text format and imported into open code software version 4.03 to facilitate coding and categorizing. The process of coding began with reading each transcript multiple times and their respective translations to ensure a degree of standardization. The coded data were compared and organized into groups. Finally, the thematic approach was used to classify and organize data according to key categories. The findings encompass direct quotes of women and narrated as without editing the grammar to avoid loss of its meaning. Quotes that best described the several categories and stated the frequently mentioned idea were chosen from several groups. 
Ethical consideration

Before conducting the study, ethical approval was obtained from the ethical review committee of the college of health science, Wolaita Sodo University. Informed written consent was obtained from study participants. The information obtained is kept confidential, and the collected data remained anonymous.

\section{Results}

\section{Socio-demographic characteristics of the participants}

We carried out ten in-depth interviews among mothers who underwent early removal of long-acting family planning methods. All study participants were married. The majority of participants, were protestant in religion. In terms of age, the participants were found between 25-32 years old, and the mean age was 29.10土 (3.01SD). The majority of the participants ( 8 out of 10) were government employees, 2 out of 10 were housewives. Half of all study participants were Diploma holder (5 out of 10)(Table 1).

Table 1: Socio-demographic characteristics of women who underwent early removal of long-acting family planning methods in Bedesa town, Wolaita Zone,2020.

\begin{tabular}{lllllll}
\hline Code & Age & Religion & Ethnicity & $\begin{array}{l}\text { Educational } \\
\text { status }\end{array}$ & $\begin{array}{l}\text { Marital } \\
\text { status }\end{array}$ & Occupation \\
\hline IDI1 & 25 & Protestant & Wolaita & Diploma & Married & $\begin{array}{l}\text { Health } \\
\text { technician }\end{array}$ \\
IDI2 & 32 & Protestant & Wolaita & Diploma & Married & government employee \\
IDI3 & 32 & protestant & Wolaita & 2 nd cycle & Married & Home manager \\
IDI4 & 25 & protestant & Wolaita & BSC & Married & Teacher \\
IDI5 & 28 & Protestant & Wolaita & Diploma & Married & Runner \\
IDI6 & 30 & Protestant & Wolaita & $2^{\text {nd }}$ cycle & Married & Merchant \\
IDI7 & 25 & Orthodox & Wolaita & High school & Married & Home manager \\
IDI8 & 30 & Protestant & Wolaita & Digree & Married & Midwives \\
IDI9 & 32 & Protestant & Wolaita & Diploma & Married & Government \\
IDI10 & 32 & Protestant & Wolaita & Diploma & Married & Government \\
\hline
\end{tabular}

\section{Family planning from user perspectives}

Majority of participants mentioned that different contraceptive methods were available in Bedesa health center. These were injectable, pills, condoms, Implanon, and IUDs. However, most of the participants had a various fear concerning family planning methods. 
Some participants had fear of procedures during insertion and removal of long-acting family planning. Delayed fertility after removal of long-acting was another frequently stated fear by the clients. Some of them perceived that, these contraceptive methods need eating special food and drinks. Some concerns of women on long-acting family planning methods were fear of death, paralysis, which causes medical illness and discomfort during sex.

"Family planning helps to prevent unplanned pregnancy ... In using contraceptives inserted under the skin; there is no need of reminding daily. When we are using oral contraceptive pills there is a need to remember frequently." $\left(\mathrm{IDI}_{4}\right) \mid$

"I feared to use loop because of the information that was circulating in the community... mothers who used loop as birth control developed paralysis... which refrained me from using it (IDI 1)".

"Implant can move in your body from arm to leg, it can stab you, and you 'can't work while the implant is in your arm. It is painful on insertion and removal; and challenging to do hard works like cooking food and washing clothes. Health workers are not interested to remove within six months after insertion". (IDI 10)

"IUD is not good during sex. It can be lost in the body and may cause foul smelling vaginal discharge". (IDI 6)

\section{Reasons for early removal of long-acting family planning}

The majority of participants mentioned that the side effects of the method were the main reason of early removal. There are different side effects mentioned for early removal of which the frequently mentioned were heavy and irregular menses, weight loss, and dizziness. The other mentioned side effects were crampy abdominal pain, skin discoloration, itching, behavioral change, numbness, burning sensation on micturation, malaisma, headache, sleep disturbance, amenorrhea, delayed fertility, dysmenorrhea, frequent hunger, thirst, weakness, difficulty of walking, and activity intolerance.

"...I decided to discontinue early because of heavy and irregular menses and weight loss. The bleeding stayed for one to two month. I also had skin discoloration and itchy skin" $\left(\mathrm{IDI}_{10}\right)$

"...Implanon was inserted for 3 years, but it was kept only for 7 months. Because, I was not comfortable, my facial skin color was changed and black patches like melasma appeared on my face. In addition to this, there was a movement in my abdomen like baby kicking during pregnancy, persistent neck pain, and absence of menses." (IDI $\left.{ }_{1}\right)$

Almost all clients received counseling services by the health care provider. However, some of them mentioned the counseling service was not adequate. 
"Health workers gave me a counseling service before inserting Implanon. However, they didn't inform me in detail about the benefits and risks of Implanon." (IDI3)

"The health care providers informed me that an implant is more advantageous than Injectable. Injectable do have effect on bone damage, cause weight gain and contains additives. Pills are also full of additives, which may lead to gastritis." (IDI ${ }_{5}$ ).

Male's involvement in contraceptive use and sharing responsibilities in reproductive life is essential. However, there was no consensus about the role of husbands in contraceptive decision making and use. Some women mentioned good support from their husbands for contraceptive use:

"...I stopped the injectable to get pregnant due to the influence made by my husband and few neighbors. Following the cessation of the injectable, I was on normal menstrual period for one year and half. Finally, I got pregnant and faced no problem during the whole pregnancy period until I gave birth at the health center." (IDI $\left.{ }_{7}\right)$

Another woman point out that husband's disapproval was one of the reasons for the early removal of Implanon "... My intention is to use Implanon for 3 years; however, my husband was against my intention. He even fought with me and bitten my hands." (IDI 10 )

\section{Desired family size}

Seeking more children was also found to be the other reason for the early removal of long-acting family planning methods. Majority of women desired two to three children. But some of them desired more than five children

“.... Even though I took Implanon according to my personal choice and voluntary base, 1 have removed it because of seeking more children." (IDI $\left.I_{2}\right)$.

\section{User's experience during and after contraceptive use}

The majority of participants sufficiently explained their lived experience of contraceptive use. The most commonly mentioned experiences were types of contraceptive methods used, duration of using contraceptives and decisions for changing from one family planning method to the other. They also said that long term use resulted in some problems with their health status.

"...Before I gave my first birth, I had been using depo. I used Jadelle after the second child. But Jadelle was removed because of side effects, and then I switched Jadelle to depo." (IDI2)

Most women perceived that they regained their health immediately after removal of long acting contraceptive method.. Furthermore, most study participants diverted their attention to short-acting contraceptives, mainly Depo-Provera. 
"...After removal of Implanon, I regained my health and peaceful life. I have changed to Depo Provera and I have been comfortable with depo. " ( $\left.\mathrm{IDI}_{10}\right)$

"... After removal of Implanon, the bleeding was not improved and I went to health center and they removed it. But the bleeding kept without showing any improvement. " (IDI $\left.{ }_{7}\right)$

\section{Participant suggestion and future plan}

Most mothers identified different sorts of opinion regarding their future plan on family methods. The most frequently mentioned suggestion were to choice family planning methods without health professional's influence and to delay contraceptive use till the first child-delivery.

“...information regarding family planning needs adequate counseling. However, Health professionals do not give adequate information. Most of the times mothers get information from the neighbours and get worried. "(IDI 10$)$

"...I visited health facility three months after Implanon insertion to take Implanon off, but the health professional did not agree to remove it before six months." (IDI $I_{8}$

\section{Discussion}

This study found that most of the participants had information about family planning methods which is consistent with a similar research conducted in Arba Minch town[6]. However, the findings of demographic and health surveys of Ethiopia showed that women in reproductive age know lesser information on family planning methods $[11,12]$. The possible reason for these differences could be due to frequent promotion or advertisement of the methods by various stakeholders. The findings of this study also showed that a low proportion of respondents had awareness of permanent methods. Our findings were also substantiated by another study from Adigrat town [13] and Nekemte town[14].

Some participants believed that the implant could move freely in the body and get lost, and they also thought that implant and IUCD cause illness. The result of this study is consistent with the study conducted on Wolaita Zone, Southern Ethiopia [15]. This might be due to the presence of rumors circulating in the community regarding long-acting family planning methods.

This study identified side effects as the main reason for the early removal of LAFP which is consistent with other studies $[8,10,16-22]$. The most frequently mentioned side effects were heavy and irregular menses, weight change, and dizziness. This finding is similar to studies conducted in Ethiopia and other low income countries $[8,17,20]$. The reason for discontinuation may be due to inadequate counseling and lack of support from health care providers.

In this study, desiring more children was recognized as one of the common reasons for early removal of long acting family planning methods which agrees with other similar studies [23-26]. Similarly, another study conducted in southern Nigeria showed that looking for more children causes a high rate of early removal of Implanon [27]. 
In this study, husband involvement was very important to use long-acting contraceptive use and to get planned family size. This finding is consistent with the study conducted in Indonesia that husbands support the utilization of long-acting contraceptive methods $[28,29]$. In contrary to this, another study showed that there is no relation with contraceptive use continuation and husband support[30].

Our study explored problems on the health care providers' counseling process. Mothers informed that the counseling was not enough and they did to allow clients to discuss their concerns freely [7]. This might also be a reason for the early removal of long-acting family planning methods.

\section{Conclusion}

Most particiapnts mentioned side effects, wrong myths and misconceptions about long-acting family methods and desired to have family size as the main reason for early removal of long-acting family planning methods. Besides, husband opposition and inadequate counseling were found to be other reasons for the early removal. Therefore, health professionals should provide adequate counseling to change the myths and misconceptions of clients on long-acting family planning methods.

\section{Abbreviations}

EDHS: Ethiopian Demographic Health Survey, FMOH: Federal Ministry of Health, IDI: Indepth Interview, LAFP: Long acting Family Planning

\section{Declarations}

Ethics approval and consent to participate: Not applicable

Consent for publication: Not applicable

Availability of data and materials

Data was uploaded as supporting files in manuscript tracking sytem

Funding: Not applicable

Competing interest: The authors declared that they have no conflict of interest.

Author's contribution:

AA, MS, LK, MW, HC, and KS have involved in conceptualization, data curation formal analysis. Acquisition, investigation, methodology, software supervision validation visualization writing original draft writing review and editing.

TT, KT, MA,GM, and ZZ have involved in data curation, formal analysis, funding acquisition, investigation, project administration, resources, supervision, validation, visualization, writing original draft, writing 
review, and editing.

Acknowledgment: We would like to acknowledge Hepi Project University for providing materials used for the work.

\section{References}

1. Royston E, Armstrong S, Organization WH: Preventing maternal deaths: World Health Organization; 1989.

2. Kesetebirhan A: National Guideline for Family Planning Services in Ethiopia. Federal Democratic Republic of Ethiopia, Ministry of Health 2011.

3. Creanga AA, Gillespie D, Karklins S, Tsui AO: Low use of contraception among poor women in Africa: an equity issue. Bulletin of the World Health Organization 2011, 89:258-266.

4. Hancock NL, Stuart GS, Tang JH, Chibwesha CJ, Stringer JS, Chi BH: Renewing focus on family planning service quality globally. Contraception and reproductive medicine 2016, 1(1):10.

5. Bongaarts J, Cleland J, Townsend JW, Bertrand JT, Gupta MD: Family planning programs for the 21st century. New York: Population Council 2012:21.

6. Utaile MM, Debere MK, Nida ET, Boneya DJ, Ergano AT: A qualitative study on reasons for early removal of Implanon among users in Arba Minch town, Gamo Goffa zone, South Ethiopia: a phenomenological approach. BMC Women's Health 2020, 20(1):1-7.

7. McDowel M: A MIXED-METHODS STUDY OF FACTORS ASSOCIATED WITH IMPLANON REMOVAL IN ETHIOPIA. In.; 2017.

8. Utaile MM, Debere MK, Nida ET, Boneya DJ, Ergano AT: A qualitative study on reasons for early removal of Implanon among users in Arba Minch town, Gamo Goffa zone, South Ethiopia: a phenomenological approach. BMC Womens Health 2020, 20(1):2.

9. Gebremariam A, Addissie A: Knowledge and perception on long acting and permanent contraceptive methods in Adigrat town, Tigray, northern Ethiopia: a qualitative study. International journal of family medicine 2014, 2014.

10. Ethiopia Csao: EFDRE. ETHIOPIA Demographic and Health Survey 2016 Key Indicators Report. In. Edited by CSAE; 2016.

11. Gebremedhin AY, Kebede Y, Gelagay AA, Habitu YA: Family planning use and its associated factors among women in the extended postpartum period in Addis Ababa, Ethiopia. Contraception and reproductive medicine $2018,3(1): 1$.

12. Tarekegn SM, Lieberman LS, Giedraitis V: Determinants of maternal health service utilization in Ethiopia: analysis of the 2011 Ethiopian Demographic and Health Survey. BMC pregnancy and childbirth 2014, 14(1):161.

13. Gebremariam A, Addissie A: Intention to use long acting and permanent contraceptive methods and factors affecting it among married women in Adigrat town, Tigray, Northern Ethiopia. Reproductive 
health 2014, 11(1):24.

14. Hambissa G, Sena L, Hiko D, Merga H: Intention to Use Long Acting and Permanent Contraceptives Methods and Associated Factors among Family Planning Clients in West Ethiopia. Fam Med Med Sci Res 2018, 7(228):2.

15. Meskele M, Mekonnen W: Factors affecting women's intention to use long acting and permanent contraceptive methods in Wolaita Zone, Southern Ethiopia: A cross-sectional study. BMC women's health 2014, 14(1):109.

16. Aminu MB, Dattijo LM, Shehu AM, Kadas SA, Chama CM: Factors responsible for discontinuation of long-term reversible contraceptives in a tertiary facility in Northeastern Nigeria. Port Harcourt Medical Journal 2019, 13(2):67.

17. Nageso A, Gebretsadik A: Discontinuation rate of Implanon and its associated factors among women who ever used Implanon in Dale District, Southern Ethiopia. BMC Womens Health 2018, 18(1):189.

18. Tadesse A, Kondale M, Agedew E, Gebremeskel F, Boti N, Oumer B: Determinant of Implanon discontinuation among women who ever used Implanon in Diguna Fango District, Wolayita zone, southern Ethiopia: a community based case control study. International journal of reproductive medicine 2017, 2017.

19. Adeagbo O, Mullick S, Pillay D, Chersich M, Morroni C, Naidoo N, Pleaner M, Rees H: Uptake and early removals of Implanon NXT in South Africa: Perceptions and attitudes of healthcare workers. South African Medical Journal 2017, 107(10).

20. Staveteig S, Mallick L, Winter R: Uptake and discontinuation of long-acting reversible contraceptives (LARCs) in low-income countries. 2015.

21. Burusie A: Reasons for Premature Removal of Implanon among Users in Arsi Zone, Oromia Region, Ethiopia, 2013. Reproductive System \& Sexual Disorders 2015, 04(01).

22. Birhane K, Hagos S, Fantahun M: Early discontinuation of implanon and its associated factors among women who ever used implanon in Ofla District, Tigray, Northern Ethiopia. International Journal of Pharma Sciences and Research 2015, 6(3):8.

23. Mesfin Mamo Utaile1* MKD, Etsehiwot Tilahun Nida2, Dube Jara Boneya3 and Amsale Tekle Ergano4: A qualitative study on reasons for early removal of Implanon among users in Arba Minch town, Gamo Goffa zone, South Ethiopia: a phenomenological approach BMC Women's Health 2020, 20(2):4-7.

24. Kalayu Birhane SG: Early discontinuation of implanon and its associated factors among womenwho ever used implanon in Ofla District, Tigray, Northern Ethiopia. International Journal of Pharma Sciences and Research (IJPSR) 2015, 6 (3):544-551.

25. Alem Gebremariam AA: intention to use long acting and permanent contrceptive methods and factors affecting it among married women in Adigrat twon, Tigray, Notrhen Ethiopia. BMC Reproductive health 2014, 11(24). 
26. Hbtamu Zerihun1 AB, Alehengn Worku3, Eyasu Desta 3, HailemariamTafesse2 ,Hika Dinss4a,Ashenafi Asmelash 5, Tadele Hailu6, Tekalihn Dmena6, , Mirgesa Kaba7, Mitike Molla7, Eshetu Girma7, Mulugeta Tamire 7 Implanon removal experience of women in Butajia, ethiopia. EthipJhealth Dev 2015, 29(3):177-180.

27. Ojule JD OE, Enyindah CE.: Experience with Implanon in southern Nigeria J Med Med Sci 2012, 3(11):710-714.

28. Bewket Zeleke L, Gella MM, Almaw Derseh H, Alemu AA, Abebe Kassahun E, Gelaw KA: Utilization of Long-Acting Contraceptive Methods and Associated Factors among Female Health Care Providers in East Gojjam Zone, Northwest Ethiopia, in 2018. BioMed research international 2019, 2019:5850629.

29. Mukamuyango J, Ingabire R, Parker R, Nyombayire J, Easter SR, Wall KM, Tichacek A, Nyirazinyoye L, Kaslow N, Allen $\mathrm{S}$ et al: Motivational interviewing to promote long-acting reversible contraception among Rwandan couples wishing to prevent or delay pregnancy. American journal of obstetrics and gynecology 2019.

30. Harzif AK, Mariana A, Malik DM, Silvia M, Lovita BT: Factors associated with the utilization of longacting reversible contraceptives among family planning clients at the Pameungpeuk Rural Hospital, Indonesia. F1000Research 2018, 7:1891.

\section{Supplementary Files}

This is a list of supplementary files associated with this preprint. Click to download.

- LAFPBedessa.opcx 